\title{
Direct identification of potato's fungal phyto-pathogens by Fourier-transform infrared (FTIR) microscopy
}

\author{
V. Erukhimovitch ${ }^{\mathrm{a}}$, L. Tsror (Lahkim) ${ }^{\mathrm{b}}$, M. Hazanovsky ${ }^{\mathrm{b}}$ and M. Huleihel ${ }^{\mathrm{c}, *}$ \\ ${ }^{a}$ Analytical Equipment Unit, Ben-Gurion University of the Negev, Beer-Sheva, Israel \\ ${ }^{\mathrm{b}}$ Department of Plant Pathology, The Institute of Plant Protection, \\ Agricultural Research Organization, Gilat Experiment Station, M.P. Negev, Israel \\ ${ }^{\mathrm{c}}$ Department of Virology and Developmental Genetics, Faculty of Health Sciences, \\ Ben-Gurion University of the Negev, Beer-Sheva, Israel
}

\begin{abstract}
Fungi are considered as serious pathogens to many plants and can cause a severe economic damage. The available methods for identification of fungi are time consuming and not always very specific. In the present study we examined the potential of FTIR microscopy for direct detection and identification of different fungal potato pathogens on the surface of potato tubers. Unique spectral bands for each of the examined fungal pathogens appeared in the spectra of naturally infected potatoes. These results strongly support the potential of FTIR microscopy for successful detection and probably discrimination between different fungal pathogens directly from the infected tissue.
\end{abstract}

Keywords: Fungal detection, fungi, FTIR microscopy, spectral peaks, potato

\section{Introduction}

Fungal pathogens cause a severe disease to various plants resulting a serious damage to large number of crops with a significant negative feedback on economy [13]. Early and reliable diagnosis methods allow the monitoring of the pathogen and enable farmers to administer suitable management strategies in a timely fashion and would greatly increase the effectiveness of the treatment [13]. There are many methods of identification of fungal phyto-pathogens, but part of them either are not fast, or reliable enough and many are expensive. Culturing of the pathogens on selective nutrient media, and morphology examination of the fungal colony using an optical microscopy [11] is among the current classical methods used for detection and identification of fungi. These procedures are time consuming, not specific and at times difficult to interpret. The enzyme-linked immunosorbent assay (ELISA) has been used as a diagnostic tool in medicine as well as in plant pathology, however, the most controversial aspect of this test is determining the "cut-off" point between a positive and negative result. Polymerase chain reaction (PCR) method is considered as a rapid and sensitive for the detection and identification of some

\footnotetext{
*Corresponding author: M. Huleihel, Department of Virology and Developmental Genetics, Faculty of Health Sciences, BenGurion University of the Negev, Beer-Sheva, Israel. Tel.: +972 8 6479867; Fax: +972 8 6479867; E-mail: mahmoudh@ bgumail. bgu.ac.il.
} 
plant pathogenic fungi $[3,6,25]$. Although this method is promising, it is not yet applied in a large-scale and still with high expenses.

Fourier transform infrared (FTIR) spectroscopy is one of the methods that have been successfully used for detecting and identifying of cancer cells [12,22], cells infected with viruses [23] and microorganisms including some fungi $[7,8,10,18-21]$. Some of these studies with microorganisms showed that discrimination was possible not only at the genus level, but also at the species level $[2,15]$. The vast majority of these studies were conducted with bacteria and very few studies involved fungi. The potential of FTIR spectroscopy as a tool for detection and identification of fungal pathogens in agriculture promises to be of a great value because of its sensitivity, rapidity, low expense and simplicity [14]. This together with the large information already known about spectral peaks obtained from FTIR spectra of living cells [4], make FTIR spectroscopy as an attractive technique for detection and identification of pathogens. This technique appears to be also as a very promising tool for the study of fungal metabolism and interactions with drugs [21,24,25,27].

The present study focuses on investigating the use of FTIR microscopy for rapid discrimination of three potato fungal pathogens directly on the surface of the intact potato tuber.

\section{Materials and methods}

\subsection{Fungi}

In the present study we examined three different potato fungal pathogens [Colletotrichum coccodes (Col), Rhizoctonia (Rh) and Helminthosporium (Hel)] which cause a serious damage to potatoes worldwide. Ten pathogens were isolated from naturally infected potato tubers. The fungi were cultured on potato dextrose agar (PDA) (Difco) and incubated in the dark at $25^{\circ} \mathrm{C}$ for 7 days. Conidia were transferred to plates of solid SA medium (0.2\% sorbose, $1.5 \%$ agar, 100 p.p.m. streptomycin sulphate) and incubated for $24 \mathrm{~h}$ at $25^{\circ} \mathrm{C}$ in the dark. Monoconidial cultures were obtained from each isolate (by micromanipulation) and maintained on Czapek dox agar (CDA) (Difco).

These fungal pathogens were examined by FTIR microscopy both directly from the infected potato tubers and also from the cultivated isolates.

Ten samples from different infected potato tubers with each of these fungal pathogens were examined.

\subsection{Sample preparation}

Since ordinary glass slides exhibit strong absorption in the wavelength range of interest to us, we used zinc selenide crystals, which are highly transparent to IR radiation.

\subsection{Preparation of infected potato and disease-free tissue samples}

Thin samples (about $20 \mu \mathrm{m}$ thickness) of samples were scratched from the infected or uninfected areas on the surface of potato tubers, suspended in $100 \mu \mathrm{l}$ of distilled sterile $\mathrm{H}_{2} \mathrm{O}$, pelleted by centrifugation at $1000 \mathrm{rpm}$ for $2 \mathrm{~min}$. Each pellet was suspended with $20 \mu \mathrm{l}$ of $\mathrm{dH}_{2} \mathrm{O}$ and a drop of $1 \mu \mathrm{l}$ of the obtained suspension was placed in a certain area on the zinc selenide crystal, air dried for $15 \mathrm{~min}$ at room temperature (or for 5 min by air drying in a laminar flow) and examined by FTIR microscopy. 


\subsection{Preparation of purified fungal samples}

A small samples of fungal pathogen were obtained from infected areas of potato tubers and grown on potato dextrose agar as mentioned above. Samples of these fungi were purified from the media by spinning about $1 \mathrm{ml}$ of medium containing fungi at $2000 \mathrm{rpm}$ for $5 \mathrm{~min}$, washing twice with $\mathrm{H}_{2} \mathrm{O}$ and the pellet was suspended in appropriate volume of $\mathrm{H}_{2} \mathrm{O}$ (about $50 \mu \mathrm{l}$ ). A drop of $1 \mu \mathrm{l}$ of the obtained suspension was placed on the zinc sellenide crystal, air dried and examined by FTIR microscopy.

\subsection{FTIR spectra measurement}

FTIR measurements were performed in the transmission mode with a liquid-nitrogen-cooled MCT detector of the FTIR microscope (Bruker IRScope II) coupled to an FTIR spectrometer (BRUKER EQUINOX model 55/S, OPUS software). The spectra were obtained in the wavenumber range of 600$4000 \mathrm{~cm}^{-1}$. Spectral resolution was set at $4 \mathrm{~cm}^{-1}$. Baseline correction by the rubber band method and vector normalization were obtained for all the spectra by OPUS software. Peak positions were determined by means of a second derivation method by OPUS software. Since the samples to be analyzed were often heterogeneous, appropriate regions were chosen by FTIR microscopy so as to eliminate different impurities (salts, medium residuals, etc.). The aperture used in this study was $50 \mu \mathrm{m}$, since this aperture gave opportunity to choose appropriate regions only from the epidermis of potato tubes without including inner parts and still good signal/noise ratio. For each sample, the spectrum was taken as the average of five different measurements at various sites of the sample. Each experiment with each sample was repeated 10 times. It is important to mention that there were no significant differences in the spectra from various sites (SD did not exceed 0.005).

\subsection{Cluster analysis}

The obtained spectral results of infected and control uninfected potato tissues were classified using cluster analysis. Cluster analysis was performed according to Ward's algorithm by OPUS software.

\section{Results}

\subsection{FTIR spectra of purified fungi and control potatoes}

The main objective of this study is examining the potential of FTIR-M for identification of fungal pathogens directly on the potatoes tubers. Since the fungi is growing on the potato surface, part of the obtained spectra of the infected area will be contaminated with spectral bands of potato sample. Therefore, it is necessary as a first step to find out the main specific fungal peaks which do not exist in the potato samples and to focus on such bands when searching for specific biomarkers for the detection and identification of fungal pathogens directly from potato tissues. So, we first compared the FTIR spectra of purified fungal pathogens, which were isolated and grown in standard culture medium, with the spectra of tissue obtained from the epidermis of uninfected tissue. Specific fungal biomarkers for each examined pathogen, which are significantly distinctive from the spectra of the tissue, will be used as a good reference for detecting and identifying the fungal pathogen in infected potato tissues. The results presented in Fig. 1 show the average FTIR spectra of the tested samples. It can be seen that there are significant differences between the spectra of the purified fungi and the control potato tissue on one 

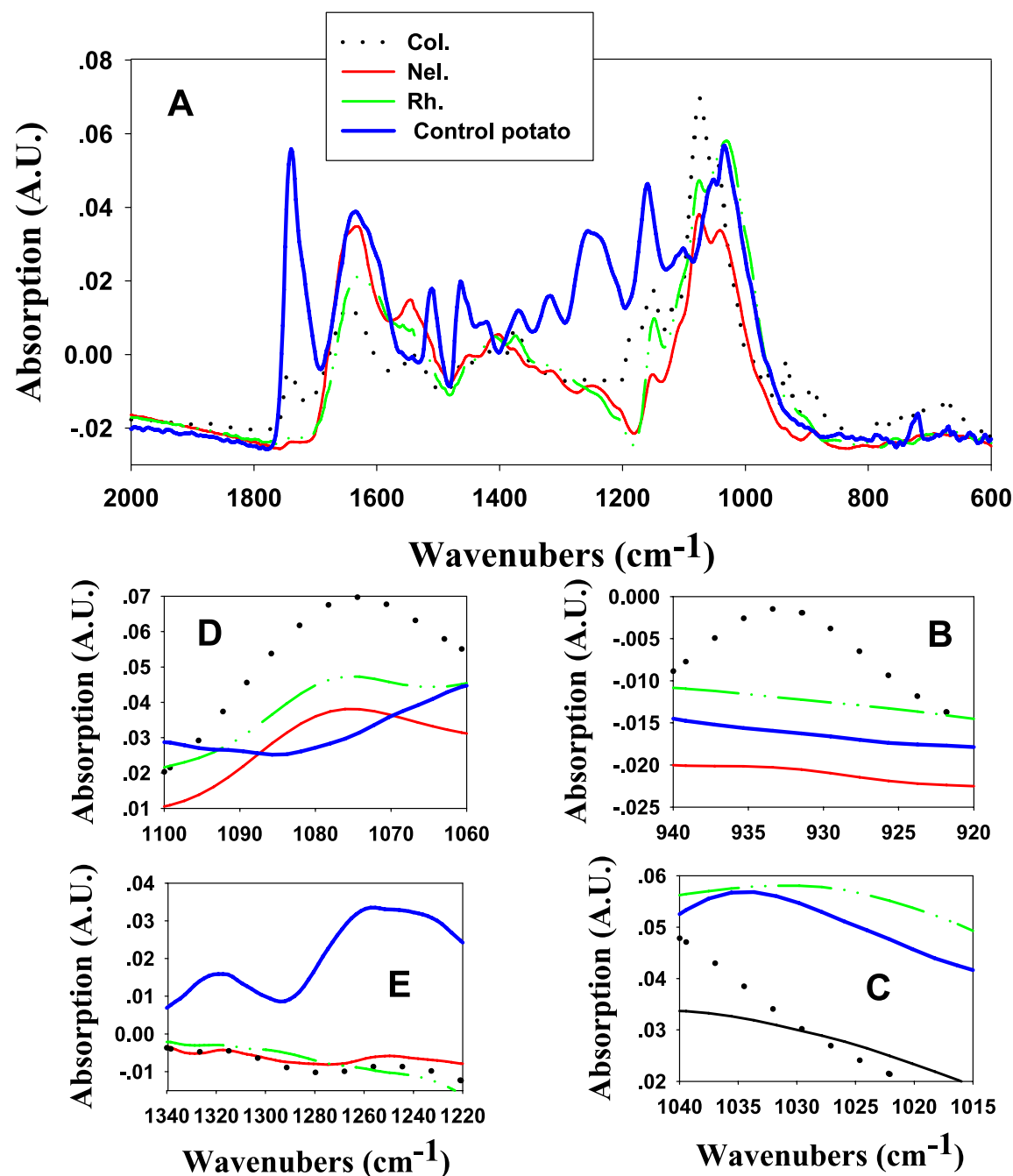

Wavenubers $\left(\mathrm{cm}^{-1}\right)$

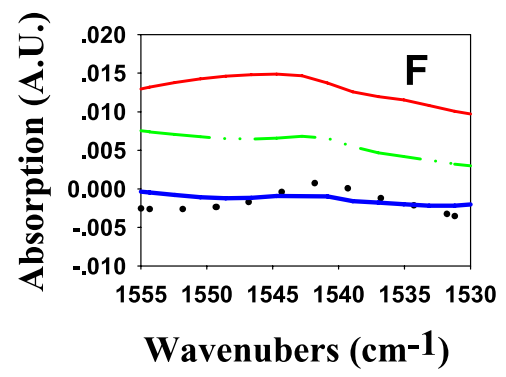

Fig. 1. FTIR spectra of purified examined fungal pathogens grown in standard medium and samples obtained from uninfected control potatoes. The obtained spectra were examined at various regions as follows: (A) $600-2000 \mathrm{~cm}^{-1}$; (B) $920-940 \mathrm{~cm}^{-1}$; (C) $1015-1040 \mathrm{~cm}^{-1}$; (D) $1060-1100 \mathrm{~cm}^{-1}$; (E) $1220-1340 \mathrm{~cm}^{-1}$ and (F) $1530-1560 \mathrm{~cm}^{-1}$. Data are means of 10 different and separate experiments for each sample. 
hand and a unique spectrum for each fungi with specific differences between them at various regions over the spectrum on the other hand.

The major consistent differences between the fungal and potato samples are as follow:

(A) Spectral bands which significantly appeared in control potato samples.

(1) Band at $1033 \mathrm{~cm}^{-1}$ (Fig. 1C). This band is assigned to carbohydrates and completely missing in all fungal samples.

(2) Bands at $1259 \mathrm{~cm}^{-1}$, assigned to syringyl ring and $\mathrm{C}-\mathrm{O}$ stretch in lignin and xylan as reported previously [14] and at $1330 \mathrm{~cm}^{-1}$ (attributed to amide III) (Fig. 1E) are strong in potato whereas, they are expressed as a slight shoulders in fungi.

(B) Spectral bands which appeared in all examined fungal pathogens samples while missing or expressed at very low intensity in control potatoes samples.

(1) Band at $1078 \mathrm{~cm}^{-1}$ (Fig. 1D). This band represents carbohydrates and it seems that fungi cells contain different carbohydrates compared to epidermal potato cells.

(2) Band at $1542 \mathrm{~cm}^{-1}$ (Fig. 1F). This band is attributed to amide II and significantly appeared in fungal samples due to the high levels of fungal proteins compared to protein levels in potato epidermal tissues. It seems that the level of protein in potato epidermal tissue is very low. This result is in agreement with the results obtained previously by Gordon et al. [9] who studied the spectral features of fungal corn and with the results of Naumann et al. [21] who examined fungi in wood.

(C) Spectral bands which are specific to each of the examined fungal pathogens.

(1) Band at $933 \mathrm{~cm}^{-1}$ (assigned to carbohydrates) is specific for Col fungi (Fig. 1B).

(2) Band at $1026 \mathrm{~cm}^{-1}$ (assigned to carbohydrates) appeared only in the spectra of fungal pathogen Rh (Fig. 1C).

(3) Band at $1543 \mathrm{~cm}^{-1}$, which is attributed to protein amide II band [26], significantly appeared only in the spectra of Hel fungi (Fig. 1F).

Potato tissues are highly rich with starch which is considered as the main component of potato tissues compared to other components such as proteins and lipids. It seems that most of the differences between the potato epidermal and the fungal spectra are due to the high levels of starch in potato tissue while starch is missing in fungi. As can be seen in Fig. 2 most of the bands in the spectrum of potato epidermal tissue are dominated by the spectral bands of the purified starch and might be affected and contributed by these bands.

These results provide a preliminary indication for possible spectral markers for the identification of fungi obtained directly from the surface of infected potatoes.

\subsection{Examination of potato samples infected with fungi}

In the present study we used control uninfected potato tubers and others which are naturally infected with the various examined fungal pathogens. The identification of these pathogens was done by standard methods as detailed in Section 2. Samples from the control uninfected potatoes were grown in the appropriate growth media in order to confirm the absence of fungal infection. For FTIR microscopy examination, thin potato samples were prepared directly from the surface of control uninfected and infected potatoes as described in M\&M. The results presented in Fig. 2 show the FTIR spectra of both 


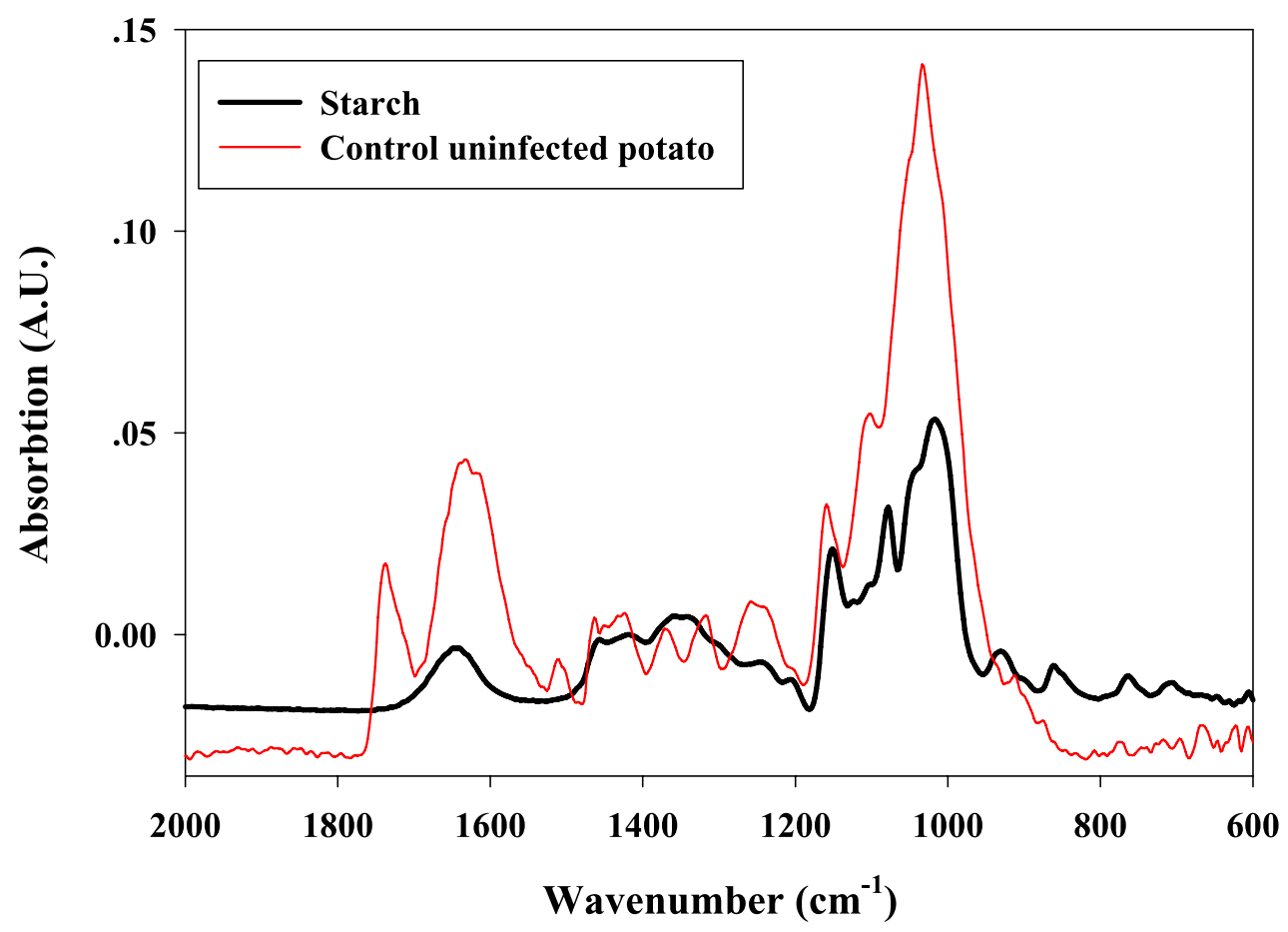

Fig. 2. FTIR spectra in the region of $600-2000 \mathrm{~cm}^{-1}$ of pure starch and samples obtained from control uninfected potato epidermis. Results are means of 20 different and separate experiments for each sample. The SD for these means was $\leqslant 0.001$.

uninfected and infected samples obtained from potatos tubers. Although there is a very high similarity between the spectra of the infected and the uninfected tissues, specific consistent spectral bands appeared in the spectra of each of the infected tissues with the different tested fungal pathogens.

These spectral bands seem to be specific to the examined fungus as detailed below:

(1) Two specific bands at 932 and $1537 \mathrm{~cm}^{-1}$ appeared in infected potato samples with Col fungus while are missing or very weakly expressed in the control uninfected samples and in those infected with the other fungi strains (Fig. 3C and F respectively, Table 1). These peaks have been shown above to be specific to the pure Col fungi (Fig. 1B and F).

(2) Band at $1028 \mathrm{~cm}^{-1}$ appeared in infected potato samples with $\mathrm{Rh}$ fungi. This peak is missing in the control uninfected samples and in those infected with the other fungi isolates (Fig. 3D and Table 1). This band just fits well with the specific peak of the pure Rh fungus mentioned above (Fig. 1C).

(3) A significant band at $756 \mathrm{~cm}^{-1}$ appeared consistently in all examined infected samples with Hel fungi (Fig. 3B and Table 1) while it is missing in the control uninfected samples and in those infected with the other fungi isolates. It is interesting to mention that this peak was not seen in the pure Hel fungal spectrum. Using these biomarkers, fully and excellent classification between the control and the infected samples with the different fungal pathogens was obtained by cluster analysis. It can also be seen that this classification method provides very good accuracy in differentiating between the various examined fungal isolates at the different fungal specific bands mentioned above (Tables 2-4). 

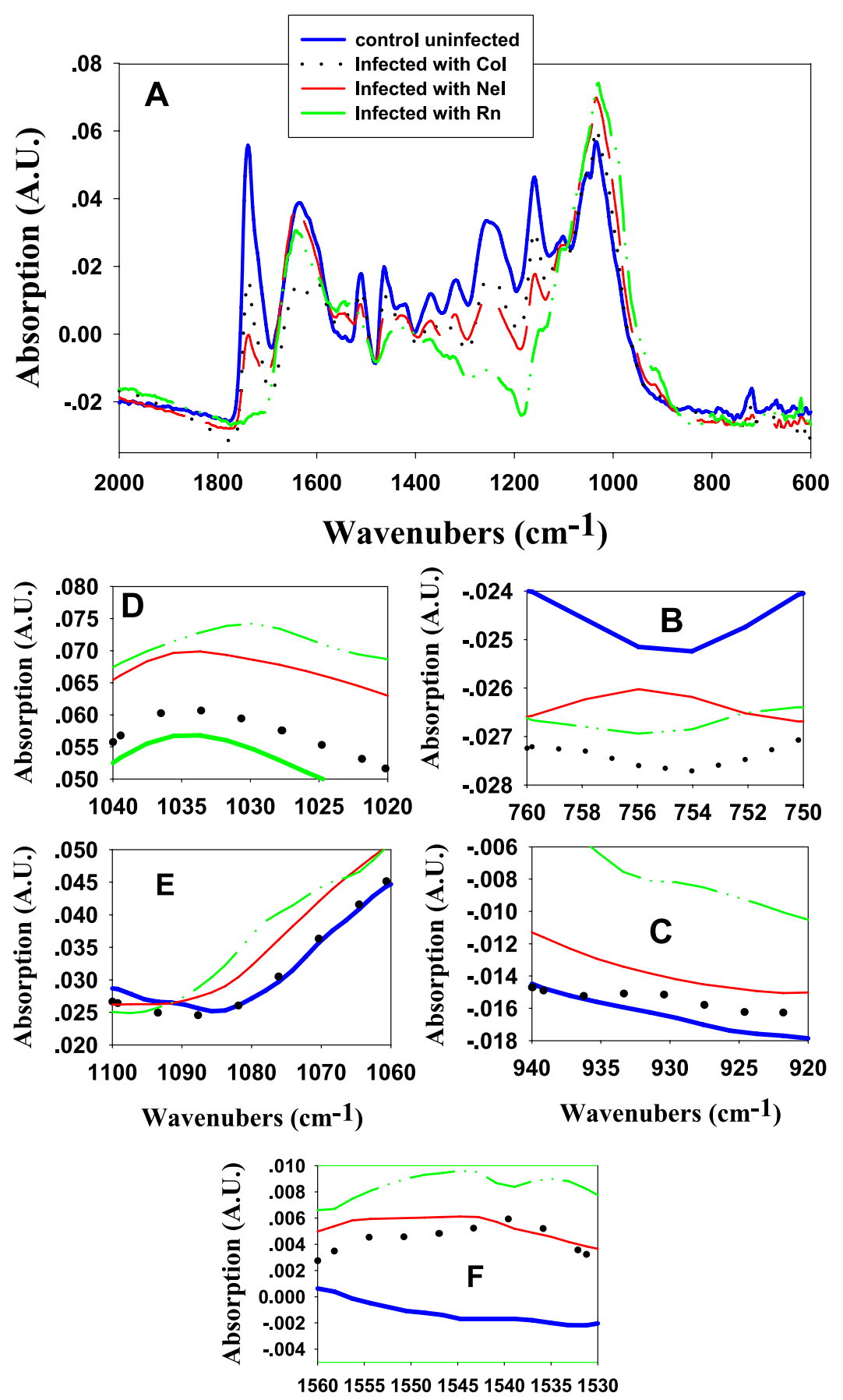

Wavenubers $\left(\mathbf{c m}^{-1}\right)$

Fig. 3. FTIR spectra of control uninfected potato samples and potato samples infected with the various examined fungal pathogens obtained by scratching technique. The obtained spectra were examined at various regions as follow: (A) 600-2000 cm-1; (B) 750-760 cm-1; (C) $920-940 \mathrm{~cm}^{-1}$; (D) $1020-1040 \mathrm{~cm}^{-1}$; (E) $1060-1100 \mathrm{~cm}^{-1} \mathrm{and}^{-10}$ (F) $1530-1555 \mathrm{~cm}^{-1}$. Data are means of 10 different and separate experiments for each sample. 
Table 1

Peak area of normal uninfected and infected potato samples with the different examined fungal pathogens at various spectral regions

\begin{tabular}{lcccc}
\hline & \multicolumn{4}{c}{ Peak area at } \\
\cline { 2 - 5 } & $756 \mathrm{~cm}^{-1}$ & $932 \mathrm{~cm}^{-1}$ & $1028 \mathrm{~cm}^{-1}$ & $1537 \mathrm{~cm}^{-1}$ \\
\hline Control potato & 0.0000 & 0.0001 & 0.0005 & 0.0001 \\
Infected with Col & 0.0005 & 0.0220 & 0.0000 & 0.0430 \\
Infected with Rh & 0.0001 & 0.0005 & 0.0350 & 0.0070 \\
Infected with Hel & 0.0680 & 0.0000 & 0.0002 & 0.0000 \\
\hline
\end{tabular}

Note: The results are means of 10 different experiments $(\mathrm{SD} \leqslant 5 \%)$.

Table 2

Relative identity (determined by cluster analysis) of normal uninfected and infected potato samples with the different examined fungal pathogens at the region $756 \mathrm{~cm}^{-1}$

\begin{tabular}{lcccc}
\hline & $\begin{array}{c}\text { Control potato } \\
(\%)\end{array}$ & $\begin{array}{c}\text { Infected with } \\
\text { Col }(\%)\end{array}$ & $\begin{array}{c}\text { Infected with } \\
\mathrm{Rh}(\%)\end{array}$ & $\begin{array}{c}\text { Infected with } \\
\text { Nel (\%) }\end{array}$ \\
\hline Control potato & 100 & 98 & 99 & 0 \\
Infected with Col & 98 & 99 & 96 & 3 \\
Infected with Rh & 99 & 96 & 100 & 1 \\
Infected with Hel & 0 & 3 & 1 & 100 \\
\hline
\end{tabular}

Table 3

Relative identity (determined by cluster analysis) of normal uninfected and infected potato samples with the different examined fungal pathogens at the regions 932 and $1537 \mathrm{~cm}^{-1}$

\begin{tabular}{|c|c|c|c|c|c|c|c|c|}
\hline & \multicolumn{2}{|c|}{$\begin{array}{c}\text { Control potato } \\
(\%)\end{array}$} & \multicolumn{2}{|c|}{$\begin{array}{c}\text { Infected with } \\
\text { Col }(\%)\end{array}$} & \multicolumn{2}{|c|}{$\begin{array}{c}\text { Infected with } \\
\text { Rh }(\%)\end{array}$} & \multicolumn{2}{|c|}{$\begin{array}{c}\text { Infected with } \\
\text { Hel }(\%)\end{array}$} \\
\hline & 932 & 1537 & 932 & 1537 & 932 & 1537 & 932 & 1537 \\
\hline Control potato & 100 & 100 & 0 & 0 & 95 & 74 & 100 & 68 \\
\hline Infected with Col & 0 & 0 & 100 & 100 & 5 & 19 & 0 & 17 \\
\hline Infected with Rh & 95 & 26 & 5 & 19 & 100 & 94 & 96 & 78 \\
\hline Infected with Hel & 100 & 68 & 0 & 17 & 96 & 93 & 100 & 96 \\
\hline
\end{tabular}

Table 4

Relative identity (determined by cluster analysis) of normal uninfected and infected potato samples with the different examined fungal pathogens at the regions $1028 \mathrm{~cm}^{-1}$

\begin{tabular}{lcccc}
\hline & $\begin{array}{c}\text { Control potato } \\
(\%)\end{array}$ & $\begin{array}{c}\text { Infected with } \\
\mathrm{Col}(\%)\end{array}$ & $\begin{array}{c}\text { Infected with } \\
\mathrm{Rh}(\%)\end{array}$ & $\begin{array}{c}\text { Infected with } \\
\text { Hel }(\%)\end{array}$ \\
\hline Control potato & 100 & 95 & 0 & 96 \\
Infected with Col & 95 & 100 & 3 & 97 \\
Infected with Rh & 0 & 3 & 99 & 4 \\
Infected with Hel & 96 & 97 & 0 & 100 \\
\hline
\end{tabular}




\section{Discussion}

In the present study we examined the potential of FTIR microscopy for an easy and rapid detection and identification of fungal pathogens directly from the surface of infected potatoes, as a representative model for an in vivo rapid detection of plant fungal pathogens. Fungal pathogens are involved in various plant diseases which can cause a serious damage to large number of crops [13]. Therefore, early and reliable diagnosis methods might be critical for controlling the spread of these pathogens [13].

The main routinely used identification method of fungi is based on their physiological properties which are time consuming, not specific and some times difficult to interpret [11].

The results obtained in this study provide unique, consistent and significant spectral biomarkers for the identification of infected regions with different fungal pathogens. Two specific bands at 932 and $1537 \mathrm{~cm}^{-1}$ seem to be specific to Col fungi because they were missing or very weakly expressed both in the control uninfected and in all the other infected samples with the different fungi strains (Fig. 2C and F, Table 1). These peaks have been shown also to be specific to the pure Col fungi (Fig. 1B and F). A significant band at $1028 \mathrm{~cm}^{-1}$ appears to be specific to Rh fungi (Fig. 3D and Table 1) and also fits well with the pure Rh fungi (Fig. 1C). However, a significant band at $756 \mathrm{~cm}^{-1}$ appeared consistently only in all examined infected samples with Nel fungi (Fig. 3B and Table 1) but it was not seen in the pure Hel fungi spectrum. Its significant appearance in infected potatoes is probably a result of a specific enzymatic degradation of potato component (most likely starch).

These specific spectral bands can be considered as good biomarkers for the detection of the appropriate fungal pathogen isolates. Although it is well known that fungal pathogens have various enzymes that can specifically digest cellulose, pectin, starch and other potato components [1], it seems that most of the above discussed spectral bands are not a result of such specific or nonspecific degradation due to the following reasons: (a) these bands appeared consistently in all examined infected samples of each pathogen; (b) they are different according to the infecting fungi and specific to that fungi and (c) these bands (except the band at $756 \mathrm{~cm}^{-1}$ which appeared consistently in all examined infected samples with Hel fungi) fits very well with specific peak of the pure appropriate fungus (as can be seen in Fig. 1).

Using these biomarkers it was possible to successfully discriminate between the different examined fungi by cluster analysis (Tables 2-4).

In addition, it is worthwhile to mention that the spectra of the uninfected control potato tubers obtained in this study were very similar to the spectra of uninfected wood previously published by Naumann et al. [21]. Whereas, the spectra of potato infected with the examined different fungal pathogens were completely distinguished from the spectra of infected woods with different fungi as presented by Naumann et al. [21]. These results together may indicate the potential of FTIR microscopy for rapid and accurate detection and discrimination between various plant fungal pathogens.

Additionally, the fact that the final results could be obtained from the infected tuber during a very short time (approximately $30 \mathrm{~min}$ ) from a small amount of sample and by a simple procedure, support the possibility of developing FTIR spectroscopy as a reliable method for rapid identification and discrimination between fungal pathogens.

\section{Conclusions}

In the present study we examined the potential of FTIR microscopy for an easy and rapid detection and identification of fungal pathogens directly from the surface of infected potatoes, as a representative model for in vivo rapid detection of plant fungal pathogens. The results obtained in this study 
provide unique, consistent and significant spectral biomarkers for infected region with different fungal pathogens. Using these biomarkers it is possible to discriminate between the different examined fungi.

Additionally, the fact that the final results could be obtained from the infected tuber during a very short time (approximately $30 \mathrm{~min}$ ) from a small amount of sample and by a simple procedure, support the possibility of developing FTIR spectroscopy as a reliable method for rapid identification and discrimination between fungal pathogens in plants infections.

\section{References}

[1] G.N. Agrios, Plant Pathology, 4th edition, Academic Press, San Diego, CA, 1997.

[2] S.H. Beattie, C. Holt, D. Hirst and A.G. Williams, Discrimination among Bacillus cereus, B. mycoides and B. thuringiensis and some other species of the genus Bacillus by Fourier transform infrared spectroscopy, FEMS Microbiol. Lett. 164 (1998), 201-203.

[3] P.W.G. Chu, P.M. Waterhouse, R.R. Martin and W.L. Gerlach, New approaches for the detection of microbial plant pathogens, Genetic Eng. Rev. 7 (1989), 45-61.

[4] M. Diem, S. Boydstom-White and L. Chiriboga, Infrared spectroscopy of cells and tissues: shining light onto a novel subject, Appl. Spectroscopy 53 (1999), 148-161.

[5] R.K. Dukor, Vibrational spectroscopy in the detection of cancer, in: Handbook of Vibrational Spectroscopy, Wiley, Chichester, UK, 2002, pp. 3335-3345.

[6] D. Errampalli, J. Saunder and D. Cullen, A PCR-based method for detection of potato pathogen, Helminthosporium solani, in silver scurf infected tuber tissue and soil, J. Microbiol. Methods 44 (2001), 59-68.

[7] V. Erukhimovitch, L. Tsor, M. Hazanovsky, M. Talyshinsky, I. Mukmanov, Y. Souprun and M. Huleihel, Identification of fungal phyto-pathogens by Fourier-transform infrared (FTIR) microscopy, J. Agric. Technol. 1 (2005) 145-152.

[8] V. Erukhimovitch, L. Tsor, M. Hazanovsky, M. Talyshinsky, I. Mukmanov, Y. Souprun and M. Huleihel, Early and rapid detection of potato's fungal infection by Fourier-transform infrared (FTIR) microscopy, Appl. Spectrosc. 61 (2007), 10521056.

[9] S.H. Gordon, R.B. Schudy, B.C. Wheeler, D.T. Wicklow and R.V. Greene, Identification of Fourier transform infrared photoacoustic spectral features for detection of Aspergillus flavus infection in corn, Int. J. Food Microbiol. 47 (1997), 5267-5272.

[10] S.H. Gordon, R.W. Jones, J.F. McClell, D.T. Wicklow and R.V. Greene, Transient infrared spectroscopy for detection of toxigenic fungi in corn: potential for on-line evaluation, J. Agric. Food Chem. 47 (1999), 5267-5272.

[11] R.C. Hamelin, P. Berube, M. Gignae and M. Bourassa, Identification of root rot fungi in nursery seedlings by nested multiplex PCR, Microbiology 62 (1996), 4026-4031.

[12] M. Huleihel, V. Erukhimovitch, M. Talyshinsky and M. Karpasas, Spectroscopic characterization of normal primary and malignant cells transformed by retroviruses, Appl. Spectroscopy 56 (2002), 640-645.

[13] Y. Katan, Principles in plant pathology, in: J. Rotem, J. Palti and Y. Ben-Yephet, eds, Volcani Center, Bet-Dagan, Israel, 1998, pp. 25-43.

[14] M. Kummerle, S. Scher and H. Seiler, Rapid and reliable identification of food borne yeasts by Fourier-transform infrared spectroscopy, Appl. Environ. Microbiol. 64 (1998), 2207-2214.

[15] D. Lefier, D. Hirst, C. Holt and A.G. Williams, Effect of sampling procedure and strain variation in Listeria monocytogenes on the discrimination of species in the genus Listeria by Fourier transform infrared spectroscopy and canonical variates analysis, FEMS Microbiol. Lett. 147 (1997), 45-48.

[16] H. Lamprell, G. Mazerolles, A. Kodjo, J.F. Chamba, Y. Noe and E. Beuvier, Discrimination of Staphylococcus aureus strains from different species of Staphylococcus using Fourier transform infrared (FTIR) spectroscopy, Int. J. Food Microb. 108 (2006), 125-129.

[17] R. Linker and L. Tsror, Discrimination of soil-borne fungi using Fourier transform infrared attenuated total reflectance spectroscopy, Appl. Spectrosc. 62 (2008), 302-305.

[18] L. Mariey, J.P. Signolle, C. Amiel and J. Travert, Discrimination, classification, identification of microorganisms using FTIR spectroscopy and chemometrics, Vib. Spectrosc. 26 (2001), 151-159.

[19] K. Maquelin, C. Kirschner, L.P. Choo-Smith, N.A. Ngo-Thi, V. Vreewijk, M. Stammler, H.P. Endtz, H.A. Bruining, D. Naumann and G.J. Puppels, Prospective study of the performance of vibrational spectroscopies for rapid identification of bacterial and fungal pathogens recovered from blood cultures, J. Clin. Microbiol. 41 (2003), 324-329.

[20] D. Naumann, The characterisation of microorganisms by Fourier-transform infrared spectroscopy (FT-IR), in: Modern Techniques for Rapid Microbiological Analysis, W.H. Nelson, ed., VHC, New York, 1991, pp. 43-55. 
[21] A. Naumann, M. Navarro-Gonzalez, S. Peddireddi, U. Kues and A. Polle, Fourier transform infrared microscopy and imaging: Detection of fungi in wood, Fungal Genet. Biol. 42 (2005), 829-835.

[22] B. Rigas, K. LaGuardia, L. Qiao, P.S. Bhandare, T. Caputo and M.A. Cohenford, Infrared spectroscopic study of cervical smears in patients with HIV: implications for cervical carcinogenesis, J. Lab. Clin. Med. 35 (2000), 26-31.

[23] A. Salman, V. Erukhimovitch, M. Talyshinsky, M. Huleihil and M. Huleihel, FTIR-spectroscopic method for detection of cells infected with herpes viruses, Biopolymers 67 (2002), 406-412.

[24] G.D. Sockalingum, E.W. Bouhedja, P. Allouch, C. Mandray, R. Labia, J.M. Millot and M. Manfait, ATR-FTIR spectroscopic investigation of imipenem-susceptible and resistant Pseudomonas aeruginosa isogenic strains, Biochem. Biophys. Res. Commun. 232 (1997), 240-246.

[25] M.K. Winson, R. Goodacre, E.M. Timmins, A. Jones, B.K. Alsberg, A.M. Woodward, J.J. Rowland and D.B. Kell, Diffuse reflectance absorbance spectroscopy taking in chemo-metrics (DRASTIC). A hyperspectral FT-IR based approach to rapid screening for metabolite overproduction, Anal. Chim. Acta 348 (1997), 273-282.

[26] T.J. White, T. Bruns, S. Lee and J. Taylo, Amplification of direct sequencing of fungal ribosomal RNA genes for phylogenetics, in: PCR Protocols: A Guide to Methods and Applications, M. Innis, ed., Academic Press, San Diego, 1990, pp. 315-327.

[27] W. Zeroual, C. Choisy, S.M. Doglia, H. Bobichon, J.F. Angiboust and M. Manfait, Monitoring of bacterial growth and structural analysis as probed by FT-IR spectroscopy, Biochim. Biophys. Acta 1222 (1994), 171-178. 


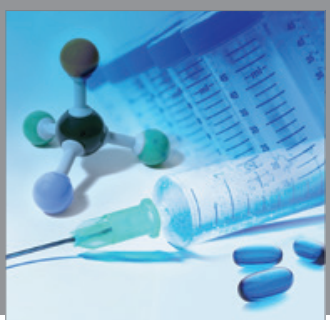

International Journal of

Medicinal Chemistry

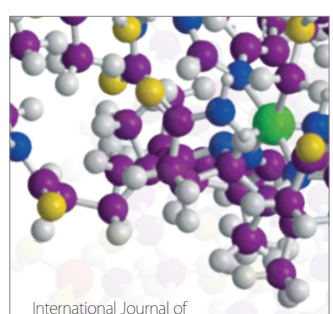

Carbohydrate Chemistry

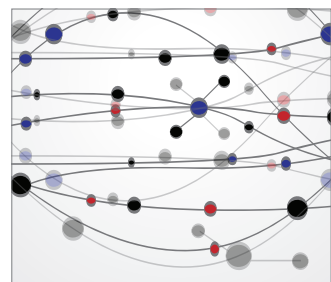

The Scientific World Journal
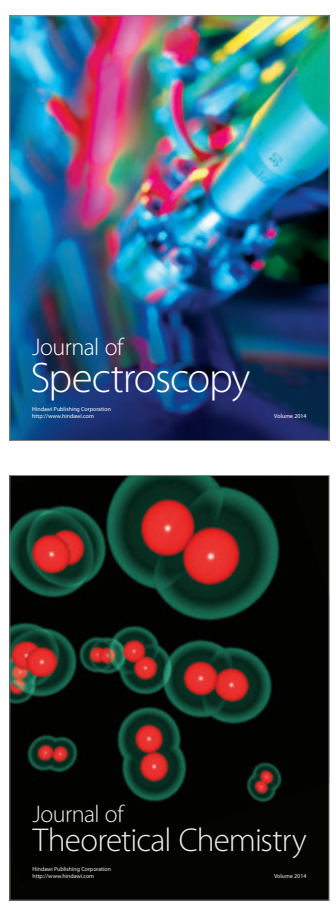
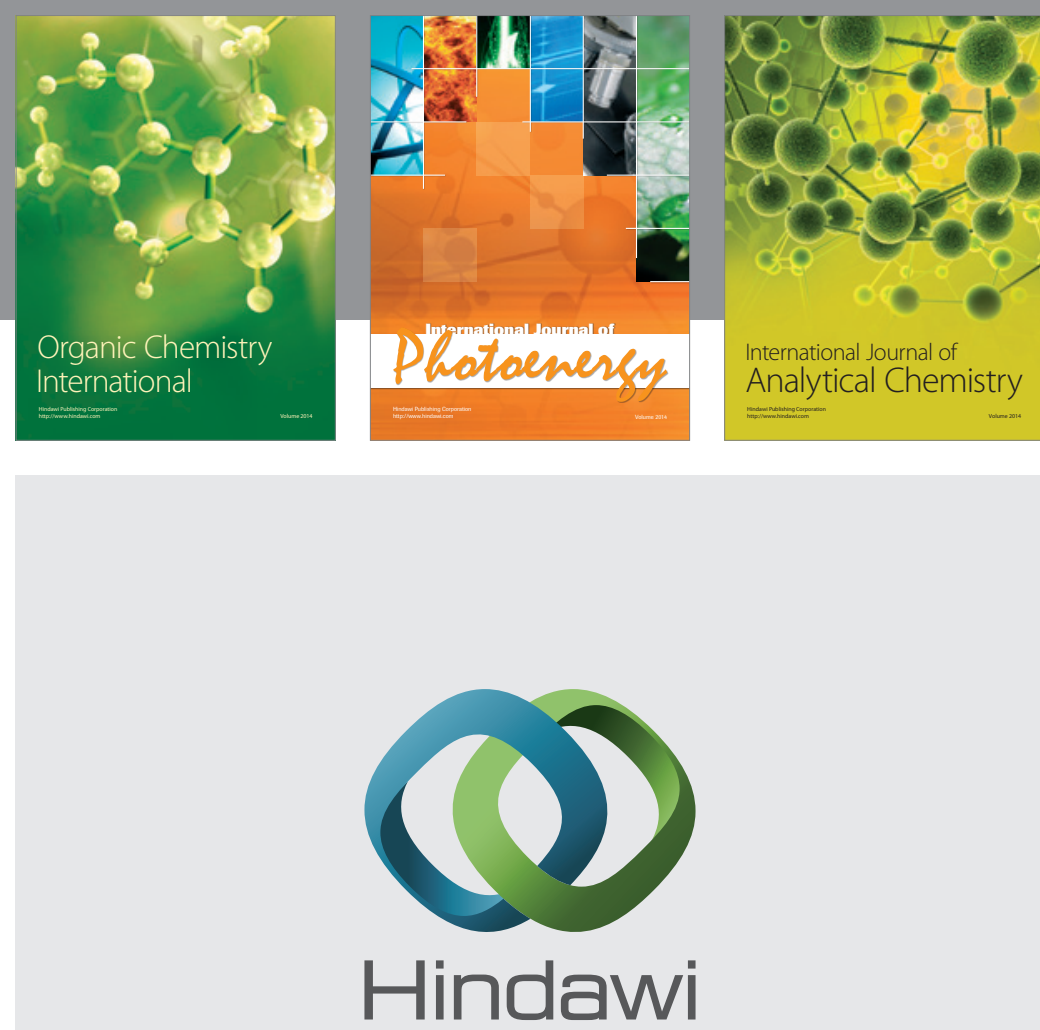

Submit your manuscripts at

http://www.hindawi.com
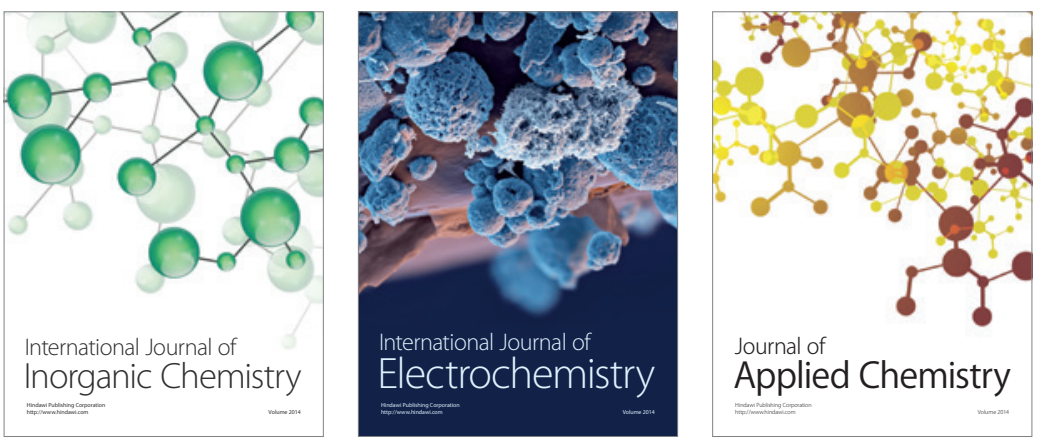

Journal of

Applied Chemistry
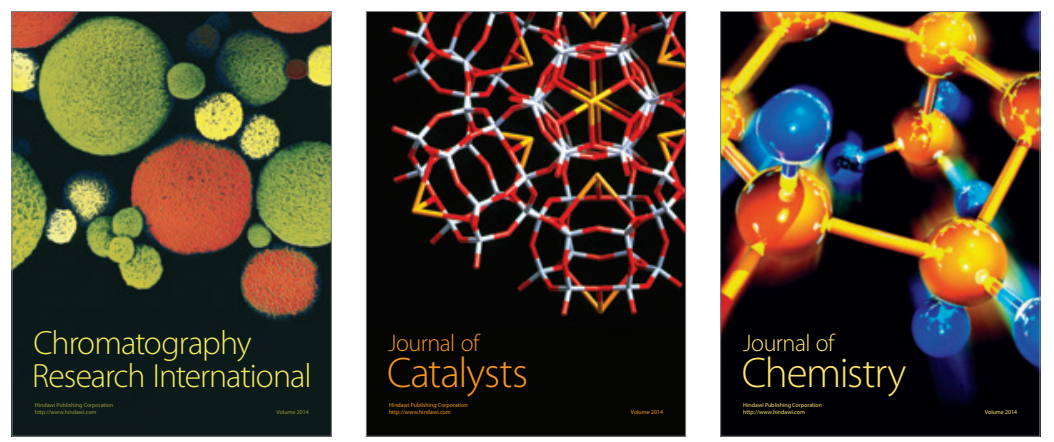
